\title{
STRUCTURAL DEFORMATION OF A RUNNING WIND TUNNEL MEASURED BY OPTICAL SCANNING
}

\author{
YANOVYCH Vitalii ${ }^{*}$, DUDA Daniel ${ }^{1}$ \\ ${ }^{1}$ University of West Bohemia, Faculty of Mechanical Engineering, Department of Power System Engineering, \\ Univerzitní 2732/8, 30100 Pilsen, Czech Republic, e-mail: yanovych@kke.zcu.cz
}

\begin{abstract}
Nowadays, the development of wind tunnels for the study of various aerodynamic phenomena is actively developing. It is possible to generate a highly laminar flow only under the condition of structural stability of the construction parts of the wind tunnel under the action of sharp pressure drops. The aim of this research is to investigate the deformation and displacement of the structural parts of the developed wind tunnel capacity of $55 \mathrm{~kW}$ depending on the velocity of the generated airflow. To estimate the amount of deformation and mutual displacement of the structural elements of the wind tunnel depending on the airflow velocity, we used the ARAMIS optical system.
\end{abstract}

KEYWORDS: wind tunnel; ARAMIS system; deformation of construction; displacement of part; flow velocity, stiffness of construction

\section{Introduction}

The development of low-speed experimental aerodynamics continues to evolve. This is very important for the development of different machines and other devices that operate under the influence of airflow. In 1960-1980, researchers have long believed that the place of subsonic wind tunnel will take computer simulation [1]. Of course, computational simulations have improved since then, but they have not come close to reaching the level to replace real experimental studies. Therefore, in most cases, modern researchers use comprehensive methods of analyzing the phenomena of Fluid Mechanics. An integral part of the real experiment is high-quality technological equipment. The main part of which is a wind tunnel with a high degree of laminar flow. Many scientific institutions are developing their wind tunnels.

For example in article [2] describes the development of a multi-purpose wind tunnel with a capacity of $15 \mathrm{~kW}$. This wind tunnel was built at the Faculty of Engineering and Built Environment, Universiti Kebangsaan, (Malaysia). Computational Fluid Dynamics simulation was used to establish the optimal geometric parameters of the tunnel and the characteristics of its flow. However, a description of the reporting measuring equipment was used to estimate the actual parameters of the generated flow.

Article [3] presents the results of a study of a new wind tunnel developed by the University of Applied Sciences in Saarbrücken (Germany). This tunnel has a closed type of Göttinger construction. The dimensions of the tunnel are $12 \times 3.5 \times 2 \mathrm{~m}$. The air is driven by a rotor with a capacity of $75 \mathrm{~kW}$, located on the upper side. The Finite Element Analysis method was used to study the characteristics of tunnel construction. This method helped to found that in different parts of the tunnel construction there are different values deformation.

The maximum value of deformation can observe at the connection with the fan. The operation of this fan creates oscillations that are transmitted to the entire body of the tunnel. However, the maximum values of deformation can be observed in the confuser that connects 
to the fan. Because in the confuser due to the action of fan oscillations and a sharp drop in pressure there is a maximum deformation. The development of the classic construction of a wind tunnel of closed type is presented in the article [4]. It shows the construction features of a low-speed wind tunnel of closed type. The maximum flow velocity in the test section is 90 $\mathrm{m} \cdot \mathrm{s}^{-1}$. The authors argue that the generated flow has a low degree of turbulence which allows you to effectively study various phenomena of aerodynamics. Wind tunnels are an efficient tool for quickly obtaining data related to the flow-through scaled or full-scale models. Given their prevalence, nature, and usefulness, the design of wind tunnels is a fairly common but difficult task.

Therefore, the authors in their article [5] investigated the main stages of designing aerodynamic low-speed wind tunnels. Based on the experimental data obtained, the authors developed recommendations for the most common parts of wind power tunnels, including flow generators, settling chamber, test section, diffuser, drive, and other additional components.

There are also a large number of low-speed open-type wind tunnels [6-9]. That is, these tunnels do not have a closed-loop for airflow. This type of construction is common. In the article [10] shown a small subsonic wind tunnel with an open circuit. The maximum flow velocity in the test section is $20 \mathrm{~m} \cdot \mathrm{s}^{-1}$, the compression ratio is 6.25 and creates maximum uniformity in the middle plane of the working section. Among the main parts of this design is a section for generating and calming the air.

One of the most common practical tasks that are solved with the help of a wind tunnel is to study the patterns of behavior of airflow around various objects. In particular, many researchers have focused on the study of turbulence [11-15]. Also, wind tunnels are often used to evaluate the adequacy of the obtained results of numerical simulations [16]. A similar situation have water tunnels, where the generated flow is used to study various hydrodynamic phenomena [17]. However, it should be noted that only wind tunnels that have a high quality of the generated flow can provide adequate experimental results.

It is clear that when developing a high-quality wind tunnel it is necessary to take into account the influence of airflow acting on its structure. This means the ability of the structure to withstand pressure drops or other mechanical factors (eg vibration). Which in turn can cause deformation of the structural elements of the tunnel and as a consequence reduce the quality of the output airflow.

To date, systems for non-contact measurement of material deformation have become widespread. These systems are very practical. Because they are making it possible to analyze the deformation of objects with complex geometry under the action of airflow.

For example, in article [18] shown the results of experimental studies of the deformation of the wings of two models of supersonic aircraft. During tests in a 9-by-7-foot supersonic wind tunnel at NASA's Ames Research Center. The method of stereophotogrammetry was used for experimental research. Measurements of deformations of surfaces of test models were carried out due to the simultaneous shooting of high-speed cameras from two directions. The obtained results allowed to estimate the bending and twisting parts of the studied models at different flow velocity.

A similar method was used by the authors in article [19]. Where they developed a videogrammetry method for measuring deformation, which is based on the use of paint that has a high sensitivity to pressure. They propose to use this technique to estimate unstable airelastic deformation and pressure fields on the wings of an airplane in transcranial and supersonic wind tunnels. 
The parameters of the outlet air flow mainly depend on the design of the wind tunnel. Therefore, the study of the behavior of parts of the wind tunnel structure during its operation is an actual task.

\section{Materials and methods of research}

\subsection{The wind tunnel}

An open-type wind tunnel was developed in the laboratory of power machines of the University of Western Bohemia (Fig. 1) [20-22]. This wind tunnel can generate a flow velocity $V$ of up to $90 \mathrm{~m} \cdot \mathrm{s}^{-1}$.

Among the main parts of the structure are the section for generating airflow, diffuser, settling chamber, confuser (contraction), and the test section. All parts of the wind tunnel except the flow generation section are located on one common frame.

The flow generation section has a three-phase Tamel electric motor with a capacity of 55 $\mathrm{kW}$. A radial fan is attached to the motor shaft. At maximum power, the speed of the electric motor is $2270 \mathrm{rpm}$. The air enters the wind tunnel through a cylindrical filter. The purpose of this filter is to prevent unwanted objects and pre-eliminate turbulent flows. Before entering the filter is a small nozzle to decrease pressure drop.

The airflow is pumped from the fan to the diffuser. After passing the last, the value velocity of a flow decreases but the static pressure increases. The diffuser has a rectangular inlet of $400 \times 500 \mathrm{~mm}$ and a rectangular outlet with beveled corners. The diffuser is divided into three sections. Its total length is $800 \mathrm{~mm}$. Each of the sections is a steel welded structure. Between these parts are metal screens. They enable the distribution of the airflow equally by breaking the rotating airflow caused by the fan. A flexible coupling was used to prevent the transmission of vibration from the flow generation section to the diffuser.

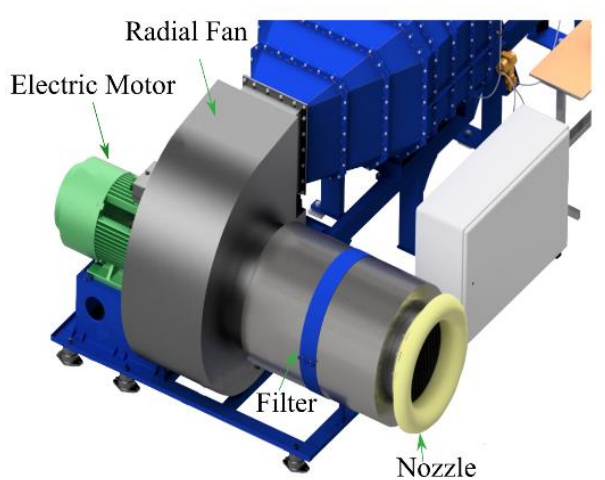

a)

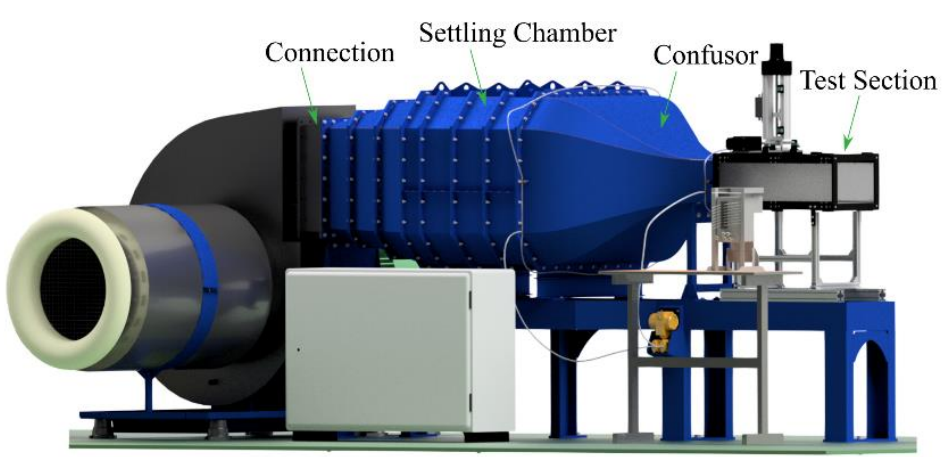

b)

Fig. 1 Construction of the wind tunnel. a) Flow generation section. b) General view of the wind tunnel

The settling chamber has a cross-section of $740 \mathrm{~mm}$. The size of the cross-section corresponds to the size of the outlet of the diffuser. The purpose of this module is to eliminate the turbulence of the flow, due to the destruction of air vortices that cause the pulse of the flow velocity. For this, the settling chamber space is divided into four separate sections, between which are installed metal screens. Each section is a steel body and allows you to equalize the pressure at the top and bottom part of the chamber. To avoid unwinding of the 
flow along its axis in the first section of the chamber is honeycomb in the form of a hexagonal membrane.

After the settling chamber the confuser is placed. It should be noted that at the outlet of the confuser the flow velocity increases significantly but decreases the static pressure. From a structural point of view, it is a metal structure with a complex configuration that ends with a suitable outlet for the test section. The length of the confuser is $920 \mathrm{~mm}$. The confuser output is connected to the testing section. Which has a rectangular shape with dimensions of $300 \times 200 \mathrm{~mm}$ and a length of $740 \mathrm{~mm}$. It is located on a subframe made of aluminum profiles attached to the mainframe. The walls of the test section are made of extruded transparent polycarbonate. The sidewalls and bottom are made of monoblock, the top cover consists of parts. This allows you to cover all or part of the measuring space, according to the needs of the experiment. The parameters of the wind tunnel were controlled using the developed program in the LabVIEW.

We used Pressure indicator Druck DPI 800 for identification the pressure drop in the confuser.

\subsection{ARAMIS system}

The main task of the wind tunnel is to generate a low degree of turbulence of the output airflow. It is clear that this parameter significantly depends on the design quality of the wind tunnel. The design of the tunnel must withstand sharp pressure drops and impulses of airflow. Vibration can also be attributed to the negative phenomena of any mechanical system. This phenomenon can occur if the rotating parts of the tunnel structure (such as an electric motor or a radial fan) have some eccentricity. In this case, the vibration will be transmitted to the entire body of the wind tunnel and will significantly degrade the quality of airflow. That is why the study of deformation and mutual displacement of the main parts of the wind tunnel construction is an important task.

The ARAMIS non-contact optical measuring system is used for this task (Fig. 2). This system has two stereo cameras that provide active accurate monitoring of objects in threedimensional coordinates on the principle of triangulation. It performs high-precision 3D measurement in the submicrometer range, regardless of the geometry and temperature of the sample. In our case, the ARAMIS SRX system from the ARAMIS sensor family was used.

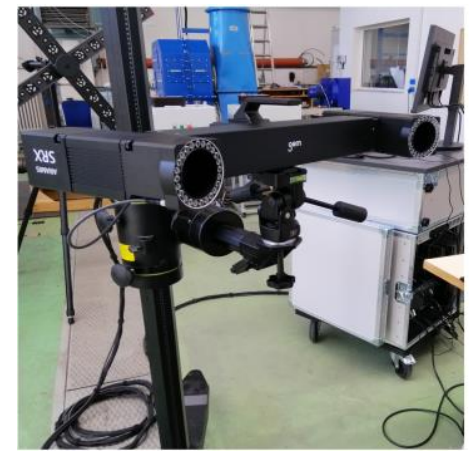

a)

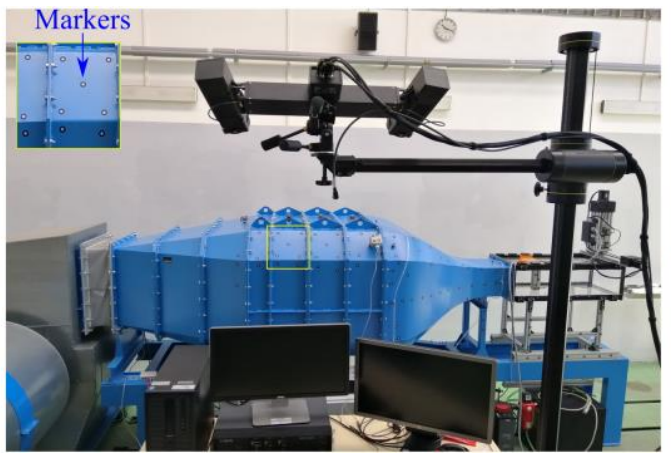

b)

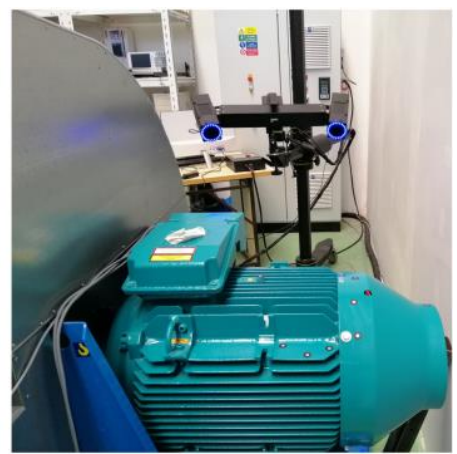

c)

Fig. 2 Using the ARAMIS system to assess the behavior of structural elements of the wind tunnel. a) ARAMIS SRX system. b) Analysis of structural deformation of the settling chamber. c) Analysis of shift of the electrical motor

This system consists of two 12-megapixel cameras that have a maximum image recording frequency of $335 \mathrm{~Hz}$. Also, by reducing the image quality, we have increased the recording 
frequency to $500 \mathrm{~Hz}$. Based on the received data from the image surface components or reference points are formed. These points are analyzed for three-dimensional displacements depending on time. In our case, markers with a diameter of $18 \mathrm{~mm}$ were used to identify reference points. The cameras were placed opposite each other on a $600 \mathrm{~mm}$ long frame.

LED lighting was used in the research. It is optimized for measurements at discrete points in areas up to $25 \mathrm{~m}^{2}$. The dual light configuration uses the effect of light reflection at reference points. This significantly reduces the exposure time to a range of a few microseconds. This feature allows us to analyze objects moving at high speed.

To analyze the behavior of the wind tunnel construction, four parts were selected: the test section, the diffuser, the settling chamber, the confuser, and the electrical motor. We also investigated how the part of the coating of the test section to which the obstacle is attached is deformed. It was used as an obstacle square profile $45 \times 45 \times 200 \mathrm{~mm}$. Part of the cover was made from wood.

Experimental studies were performed for two cases. In the first case, the behavior of the object was studied with a sharp increase and decrease in flow velocity from 0 to $76 \mathrm{~m} \cdot \mathrm{s}^{-1}$ at a recording frequency of $\lambda=3-5 \mathrm{~Hz}$. In the second case at a constant flow velocity of $76 \mathrm{~m} \cdot \mathrm{s}^{-1}$ at a recording frequency of $\lambda=500 \mathrm{~Hz}$.

\section{Results and discussion}

The ARAMIS system allows us, among others, to analyze the change in distance between two reference points. It is this distance that we will estimate in further analysis.

Fig. 3 shows the experimental results of the deformation of the test section during the operation of the wind tunnel. To measure the amount of deformation, two measuring lines $L 1$ and $L 2$ were formed. They were placed diagonally in the space between the test section and the common frame (see Fig. 3 a). Measuring line $L 1$ characterizes the shift of the farthest point of the test section relative to the confuser. Then what line $L 2$ on the contrary. As a result of the analysis of changes in the length of these lines, we obtained the dependence of the deformation of the test section on the airflow (Fig. 3 b, c, d). For each curve of experimental data, we also got a fit curve (polynomial of the sixth order). We used two different image recording frequencies $\lambda=3 \mathrm{~Hz}$ - for a sharp increase and decrease in the velocity, $\lambda=500 \mathrm{~Hz}$ for a constant velocity.

Fig. 3. b shows that the deformation of the test section with a sharp increase in airflow from 0 to $76 \mathrm{~m} \cdot \mathrm{s}^{-1}$ increases and is uneven. For the line $L 1$ the maximum deformation is $\varepsilon_{1} \approx$ $0.011 \%$ while for the line $L 2-\varepsilon_{2} \approx 0.008 \%$. This is a logical phenomenon. Because the rigidity of the structure in these places is different. There is also a significant pressure difference between the inlet and outlet of the test section. At a constant $V=76 \mathrm{~m} \cdot \mathrm{s}^{-1}$ the deformation of the test section is constant $\varepsilon_{1} \approx 0.008 \% \mathrm{~mm}$ (Fig. $3 \mathrm{c}$ ). Whereas the value of deformation $\varepsilon_{2}$ does not change.

Fig. $3 \mathrm{~d}$ shows the dependence of the amount of deformation of the test section at a sharp decrease in air velocity. We can see that at $40 \mathrm{~m} \cdot \mathrm{s}^{-1}$ the deformation disappears. It should be noted that Fig. $3 \mathrm{~d}$ shows the dependence of the value of $\varepsilon_{1}$ and $\varepsilon_{2}$ immediately after a sharp increase in the flow velocity $u$. Therefore, the final and initial values of deformation in Fig. 3 $\mathrm{b}$ and Fig. $3 \mathrm{~d}$ are almost identical. But significantly different from the values obtained in Fig. 3 c. This pattern is because, with a sharp increase in flow velocity, the deformation of the material of the test section has a somewhat inertial behavior. First, it increases sharply and then due to the stress relaxation of the material it decreases slightly. Because one part of the test section is connected to the tunnel and the other is located at a distance from it. They 
manifest the relaxation of the material in different ways. Thus, for $\varepsilon_{2}$, the shift is almost zero. Whereas for $\varepsilon_{1}$ the deformation is stabilized at $0.008 \%$.

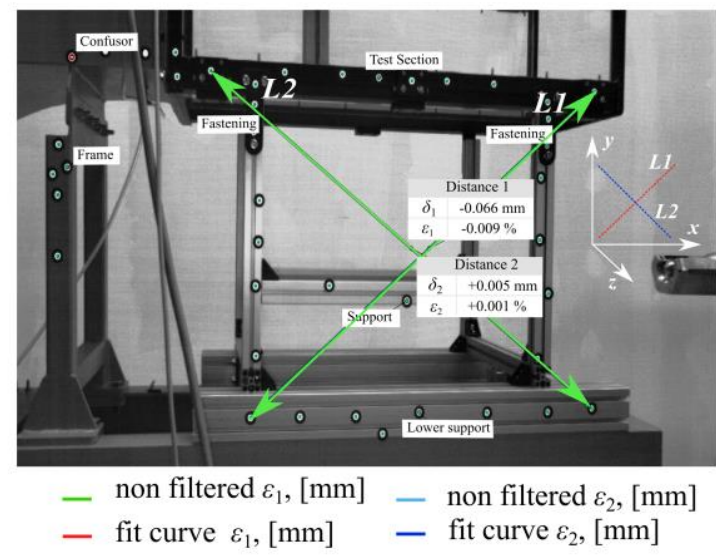

a)

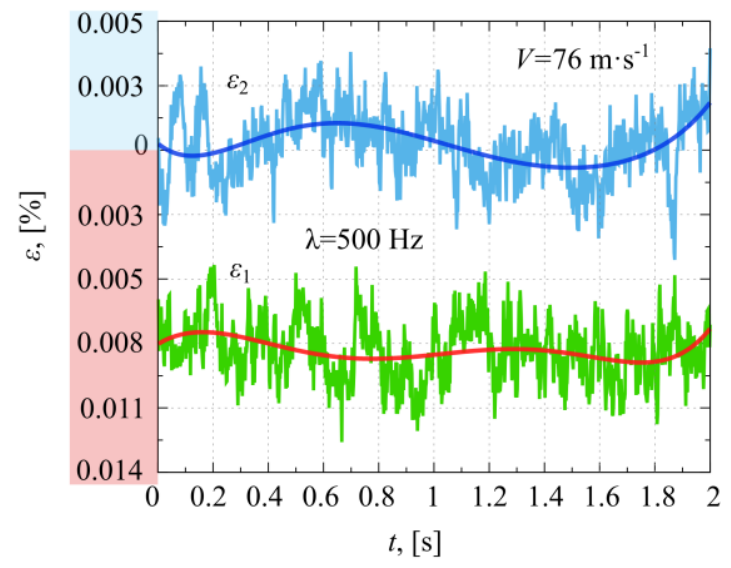

c)

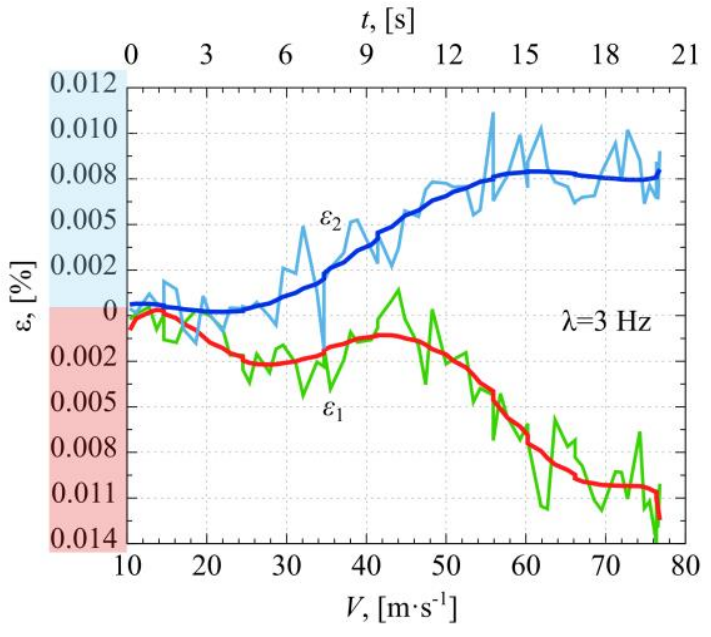

b)

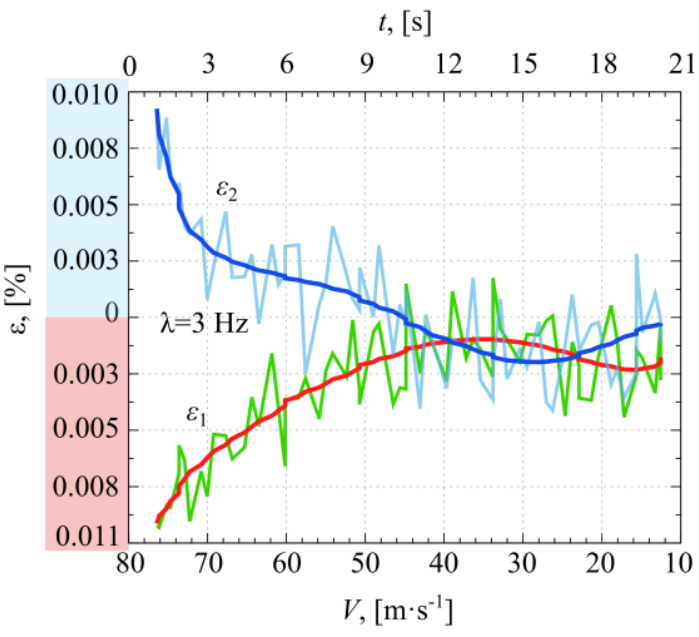

d)

Fig. 3 Deformation of the construction of the test section depending on the flow velocity. a) The position of the measuring lines between the reference points. $\delta_{1}, \delta_{2}$ - fractional change in length for $L 1$ and $L 2$ respectively. b) Deformation at a sharp increase in flow velocity from 0 to $76 \mathrm{~m} \cdot \mathrm{s}^{-1}$. c) Deformation at a constant flow velocity of $76 \mathrm{~m} \cdot \mathrm{s}^{-1}$. d) Deformation with a sharp decrease in flow velocity from $76 \mathrm{~m} \cdot \mathrm{s}^{-1}$ to $5 \mathrm{~m} \cdot \mathrm{s}^{-1}$. The blue area shows the elongation of the measuring line, red area of its reduction

The deformation of the confuser construction depending on the flow velocity is shown in Fig. 4. For this analysis, two measuring lines $L 3$ and $L 4$ were generated between the four reference points of the confuser. These lines, respectively, characterize the deformation of the confuser relative to its height and length. Experimental studies were performed with a sharp increase in flow velocity to $76 \mathrm{~m} \cdot \mathrm{s}^{-1}$ and a subsequent sharp decrease in flow velocity to 5 $\mathrm{m} \cdot \mathrm{s}^{-1}$. The recording frequency of the cameras was $\lambda=3 \mathrm{~Hz}$. As we can see, the maximum values of the deformation of the confuser relative to its height and length are observed at different flow velocity (Fig. 4 b). They also compensate each other somewhat. When the value of $\varepsilon_{3}$ increases, the value of $\varepsilon_{4}$ decreases. The maximum deformation for $\varepsilon_{4} \approx 0.006 \%$ at $V=40 \mathrm{~m} \cdot \mathrm{s}^{-1}$. Whereas the maximum value of $\varepsilon_{3} \approx 0.005 \%$ at $V=76 \mathrm{~m} \cdot \mathrm{s}^{-1}$. It is clear that the values obtained are very small. 


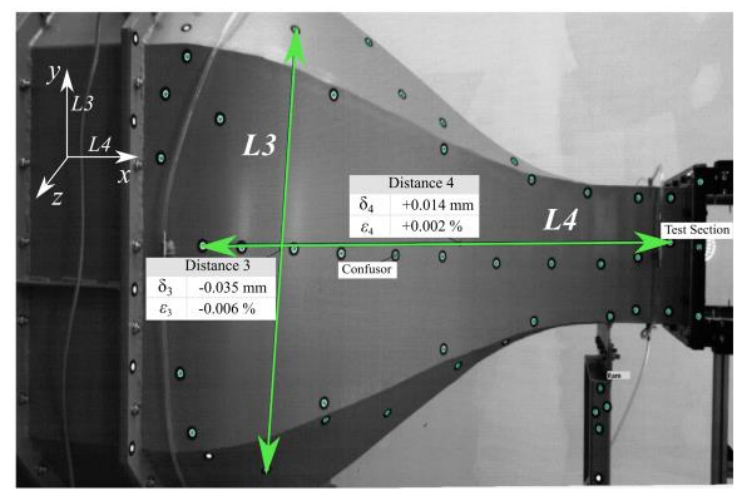

- non filtered $\varepsilon_{3},[\mathrm{~mm}]$ - fit curve $\varepsilon_{3},[\mathrm{~mm}]$

- non filtered $\varepsilon_{4},[\mathrm{~mm}]$ - fit curve $\varepsilon_{4},[\mathrm{~mm}]$

a)

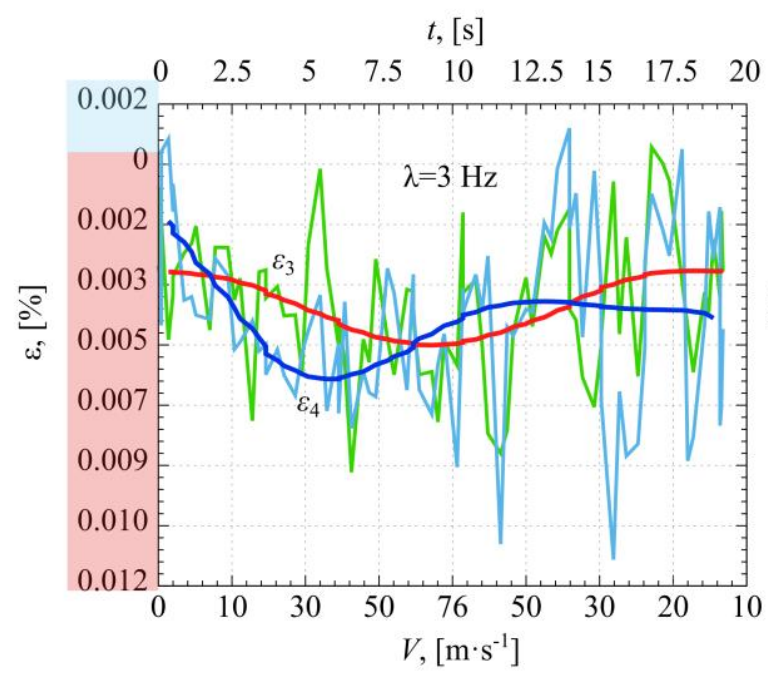

b)

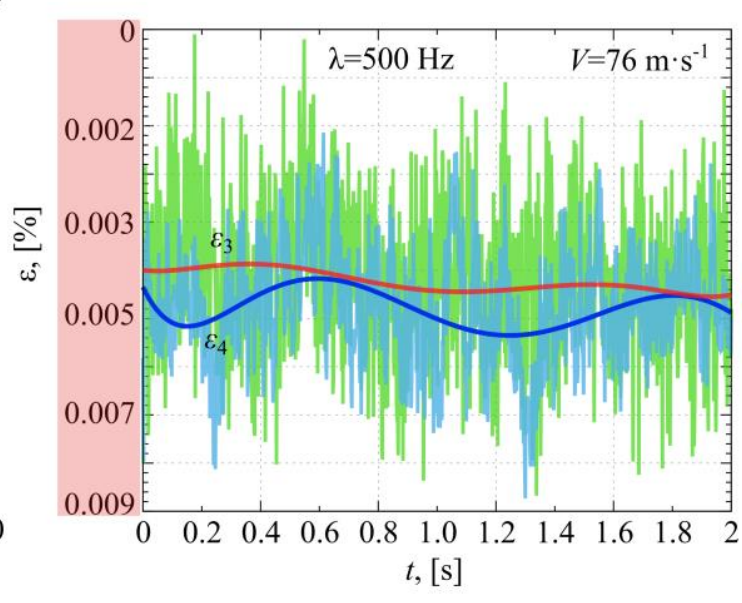

c)

Fig. 4 Dependence of deformation of the confuser construction depending on the flow velocity. a) Measuring lines between the reference points of the confuser. $L 4$ is responsible for longitudinal deformation. $L 3$ is responsible for the deformation relative to the height of the confuser. $\delta_{3}, \delta_{4}$ - fractional change in length for $L 3$ and $L 4$ respectively. b) Deformation with a sharp increase and decrease in flow velocity from 0 to $76 \mathrm{~m} \cdot \mathrm{s}^{-1}$ and then to $5 \mathrm{~m} \cdot \mathrm{s}^{-1}$. c) Deformation at a constant flow velocity of $76 \mathrm{~m} \cdot \mathrm{s}^{-1}$. The blue area shows the elongation of the measuring line, red area of its reduction

But the obtained distribution is quite logical and have a physical meaning. From Fig. $4 \mathrm{~b}$ we can see that with increasing flow velocity from the beginning there is a significant increase in deformation in the longitudinal direction. This is understandable because the static pressure at the beginning of the confuser is much higher than at the outlet. The difference between these pressures is approximately $2.4 \mathrm{kPa}$. Therefore, at first there is a slight elongation of the confuser. After that, take into account the regularity of uniform distribution of stresses in the material, the process of deformation of the confuser relative to its height begins. A further increase in the value of $\varepsilon_{3}$ will lead to a decrease in the value of $\varepsilon_{4}$. That is, there is a process of mutual compensation of the amount of deformation of the confuser in accordance with its length and height. At a constant flow velocity, the amount of deformation of the confuser is equal to $\varepsilon_{3} \approx 0.004 \%$ and $\varepsilon_{4} \approx 0.005 \%$ at $76 \mathrm{~m} \cdot \mathrm{s}^{-1}$. 
One of the main parts of the wind tunnel design is the settling chamber. The behavior of its construction under the action of pressure drops is an important factor in generating airflow with a low degree of turbulence.

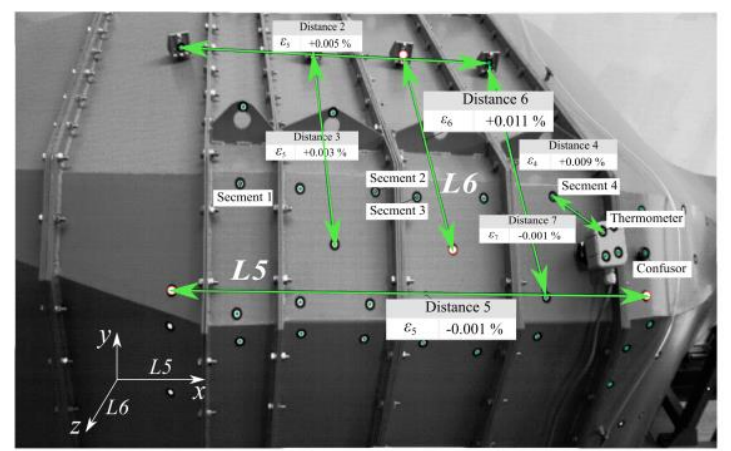

— non filtered $\varepsilon_{6},[\mathrm{~mm}]-$ non filtered $\varepsilon_{5},[\mathrm{~mm}]$

- fit curve $\varepsilon_{6},[\mathrm{~mm}] \quad$ fit curve $\varepsilon_{5},[\mathrm{~mm}]$

a)

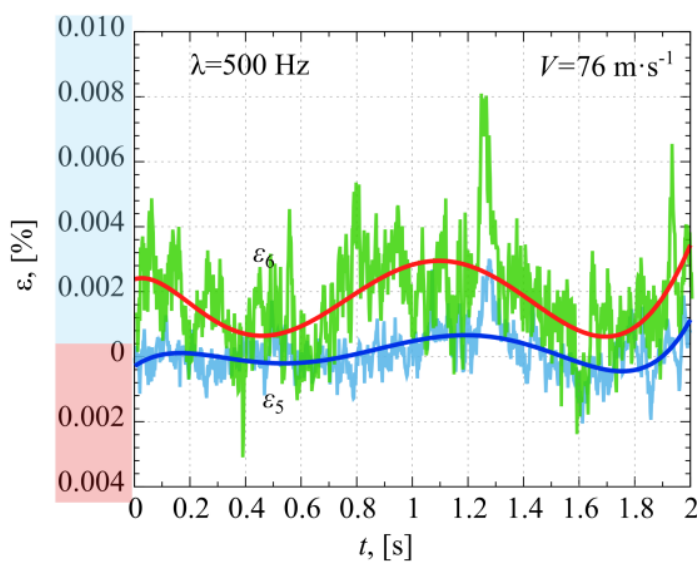

c)

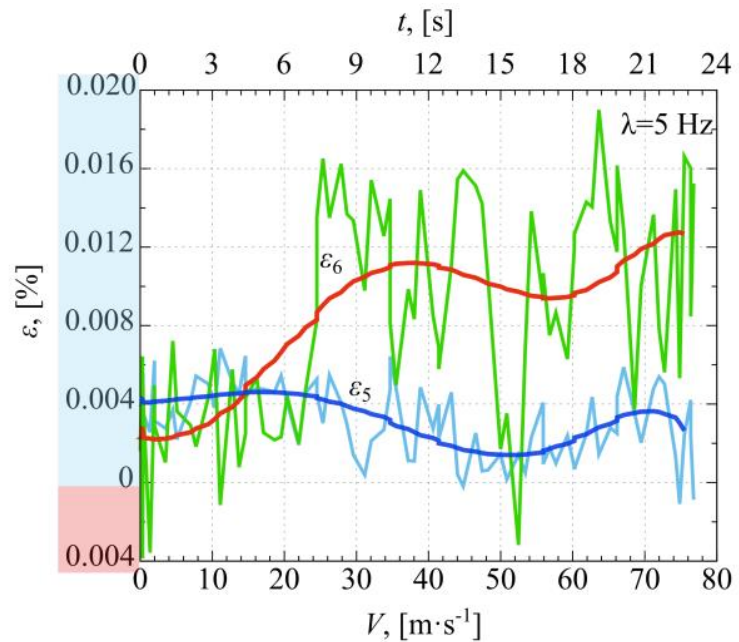

b)

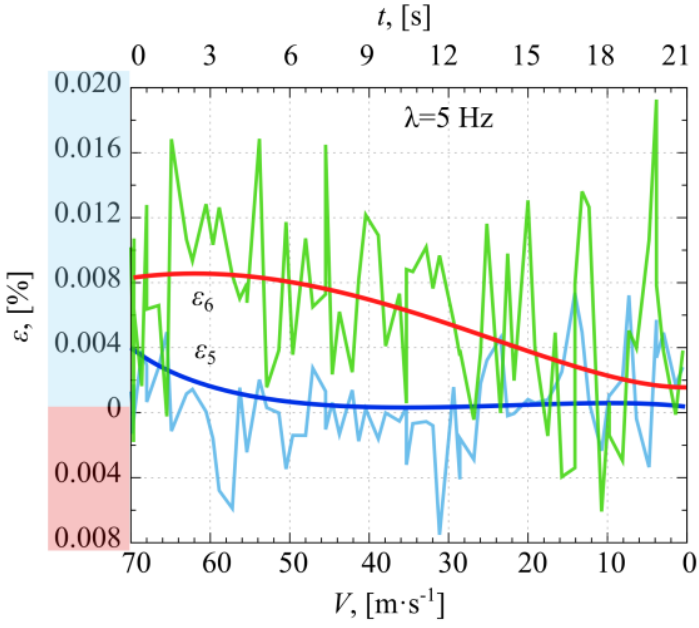

d)

Fig. 5 Evaluation of deformation of the settling chamber. a) Measuring lines between the reference points of the settling chamber. Measuring line $L 5$ is responsible for longitudinal deformation. Measuring line $L 6$ is responsible for the deformation relative to the width of the settling chamber. b) Deformation with a sharp increase flow velocity from 0 to $76 \mathrm{~m} \cdot \mathrm{s}^{-1} . \mathrm{c}$ ) Deformation at a constant flow velocity $76 \mathrm{~m} \cdot \mathrm{s}^{-1}$. d) Deformation with a sharp decrease in flow velocity from $76 \mathrm{~m} \cdot \mathrm{s}^{-1}$ to 0 . The blue area shows the elongation of the measuring line, red area of its reduction

In Fig. 5 shows the results of experimental studies of the deformation of the settling chamber depending on the different flow velocity. The experiments were performed with different camera recording frequencies. In the case of a sharp increase (Fig. 5 b) and a sharp decrease (Fig. $5 \mathrm{~d}$ ) flow velocity $\lambda=5 \mathrm{~Hz}$, at a constant flow velocity $\lambda=500 \mathrm{~Hz}$ (Fig. $5 \mathrm{c}$ ). For experimental studies, two lines between reference points were generated. Accordingly, the first line $L 5$ characterizes the longitudinal deformation of the settling chamber $\varepsilon_{5}$, the second line $L 6$ characterizes the deformation relative to its width $\varepsilon 6$. The maximum value of 
deformation at $V=76 \mathrm{~m} \cdot \mathrm{s}^{-1}$ for $\varepsilon_{5} \approx 0.004 \%$ and for $\varepsilon_{6} \approx 0.012 \%$. At a constant flow velocity of $76 \mathrm{~m} \cdot \mathrm{s}^{-1}$, the longitudinal deformation of $\varepsilon_{5}$ actually disappears. The deformation $\varepsilon_{6}$ has a sinusoidal distribution in the range between $0.001 \%$ and $0.003 \%$. We should be noted that the construction of the settling chamber has minimal deformation at a sharp increase and a decrease of flow. That allows us to provide qualitative calming of airflow.

The wind tunnel can be divided into two parts: part of the tunnel to generate airflow and part of the tunnel to calm it. A flexible coupling is used to connect them. It is clear that during the operation of the wind tunnel, the pressure difference in these parts can lead to some displacement. We investigated the displacement of the part of the tunnel to generate the flow relative to the part of the tunnel to calm the flow (Fig. 6).

We first generated five measuring lines between reference points. Lines $L 7, L 8, L 9$ show the horizontal mutual displacement $\Delta L_{7}, \Delta L_{8}, \Delta L_{9}$ of the two parts of the tunnel construction. Straight lines $L 1 O$ and $L 11$ are placed symmetrically on the diagonals of the flexible coupling and show displacement $\Delta L_{10}, \Delta L_{11}$. For each measuring line, we investigated two cases. In the first case, with a sharp increase and a sharp decrease in the flow velocity at $\lambda=4 \mathrm{~Hz}$ (Fig. $6 \mathrm{~b}$, e). In the second case at a constant flow velocity at $\lambda=500 \mathrm{~Hz}$ (Fig. $6 \mathrm{c}, \mathrm{f}$ ).

Fig. $6 \mathrm{~b}$ shows that the maximum displacement with a sharp increase in flow velocity in the horizontal plane is observed at $76 \mathrm{~m} \cdot \mathrm{s}^{-1}$ for $\Delta L_{7} \approx 0.35 \mathrm{~mm}$. At a constant flow velocity (Fig. $6 \mathrm{e}$ ) the amount of displacement remains constant $\Delta L_{7} \approx 0.21 \mathrm{~mm}, \Delta L_{8} \approx 0.13 \mathrm{~mm}, \Delta L_{9} \approx$ $0.1 \mathrm{~mm}$. Interestingly, the displacement values for $\Delta L_{8}$ and $\Delta L_{9}$ are different. Although they are placed symmetrically. This shows that the displacement occurs not only parallel to the horizontal plane. This fact is confirmed by experimental data for the displacement of $\Delta L_{10}$ and $\Delta L_{11}$ (Fig. 6 e). This Fig. shows that with a sharp increase in flow velocity, the obtained distribution of curves $\Delta L_{10}$ and $\Delta L_{11}$ is symmetric. Their maximum displacement is in the range of 0.6-0.7 mm. At a constant flow velocity of $76 \mathrm{~m} \cdot \mathrm{s}^{-1}$, the displacement for $\Delta L_{10} \approx 0.6$ $\mathrm{mm}$ and for $\Delta L_{11} \approx 0.5 \mathrm{~mm}$ (Fig. $6 \mathrm{f}$ ). In general, this phenomenon occurs due to a significant pressure drop. When injecting air flow by a radial fan to part of the tunnel to calm the flow. The airflow receives some resistance when passing through the diffuser. Because after the diffuser in the settling chamber the pressure is much higher than atmospheric. Therefore, some parts of the flow to form the so-called reverse thrust. Which acts in the opposite direction and shifts the section to generate the flow relative to the vertical plane. The obtained results confirm the need to use a flexible coupling in the production of wind tunnels.

We also investigated the magnitude of the displacement of the motor depending on the velocity of the generated flow. To estimate the displacement, two lines L12 and L13 were generated between the reference points of the motor housing and a separate base element. As you can see in Fig. 7 a in the left corner is a metal profile. It is not attached to the general construction of the wind tunnel. This can help to more accurately determine the displacement of the motor. Because reference points on the profile are always fixed. 


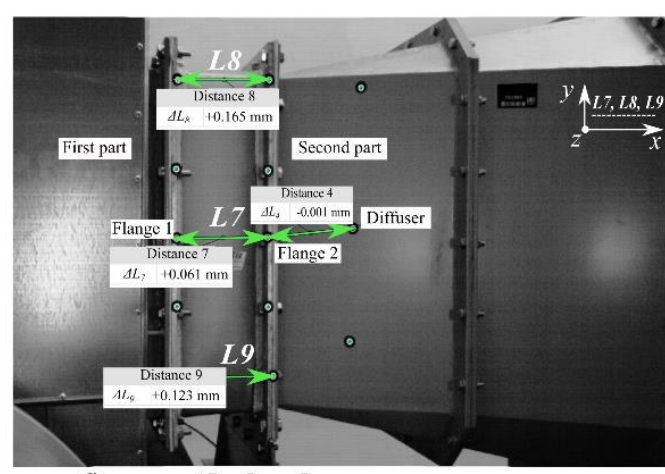

- fit curve $\Delta L_{7},[\mathrm{~mm}] \quad$ - non filtered $\Delta L_{7},[\mathrm{~mm}]$ - fit curve $\Delta L_{8},[\mathrm{~mm}]$ - non filtered $\Delta L_{8},[\mathrm{~mm}]$ - fit curve $\Delta L_{9},[\mathrm{~mm}]$ — non filtered $\Delta L_{9},[\mathrm{~mm}]$

a)

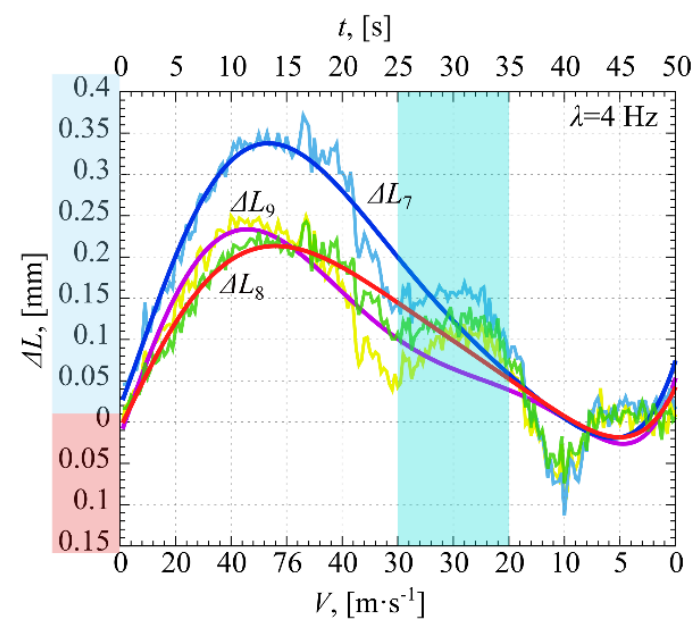

b)

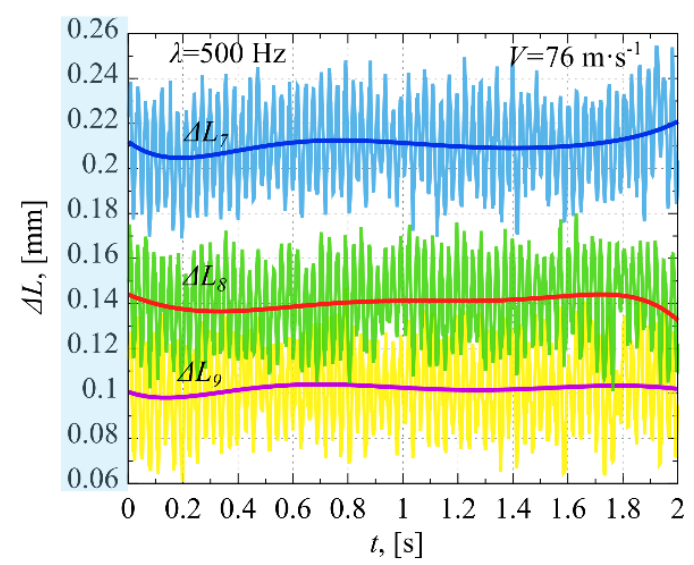

c)

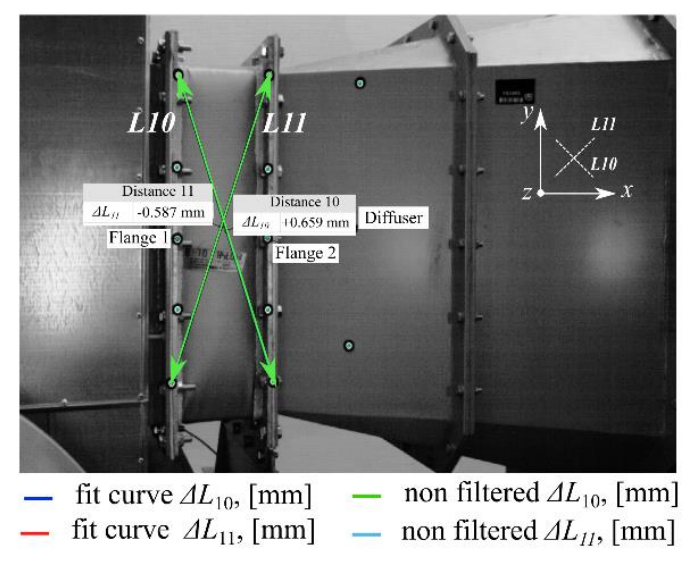

d)

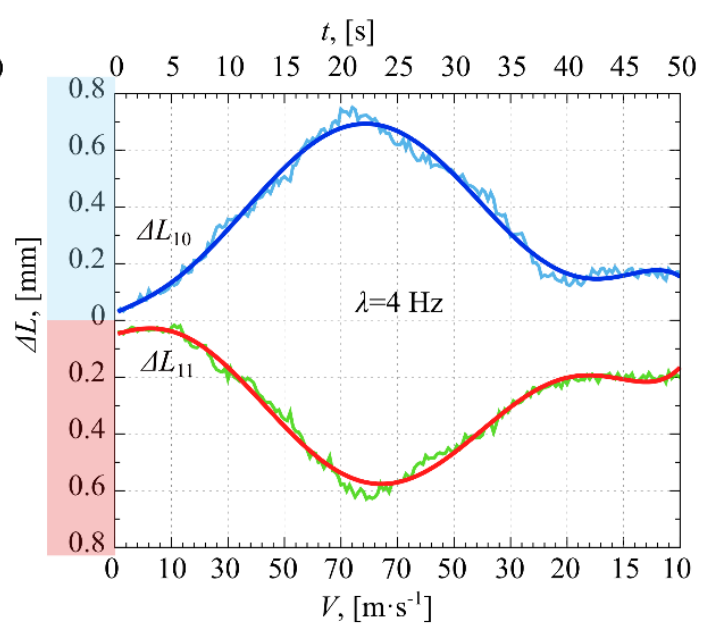

e)

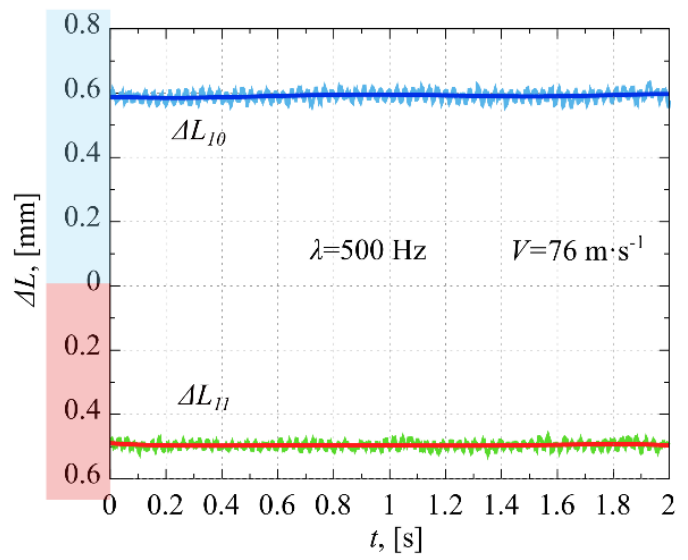

f)

Fig. 6 Estimation of relative mutual displacement of tunnel parts for generation and

calming of airflow. a), d) Measuring lines between the reference points. $L 7, L 8, L 9$ is responsible for longitudinal displacement. $L 10$ and $L 11$ are responsible for the offset relative to the diagonals of the flexible coupling. b), e) Displacement at a sharp increase and decrease in flow velocity from 0 to $76 \mathrm{~m} \cdot \mathrm{s}^{-1}$ and then to $5 \mathrm{~m} \cdot \mathrm{s}^{-1}$. c), f) Displacement at a constant flow velocity $76 \mathrm{~m} \cdot \mathrm{s}^{-1}$. The blue area shows the elongation of the measuring line, red area of its reduction 


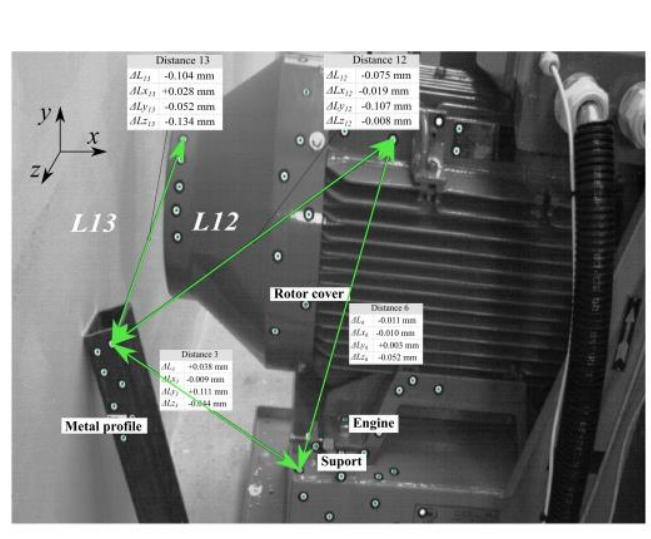

a)

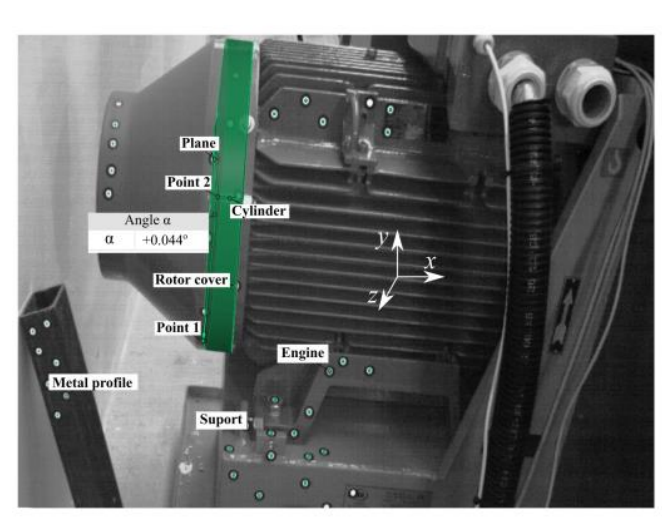

b)

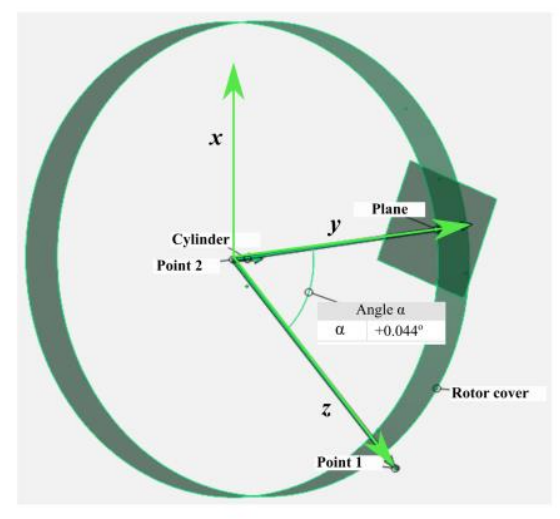

c)

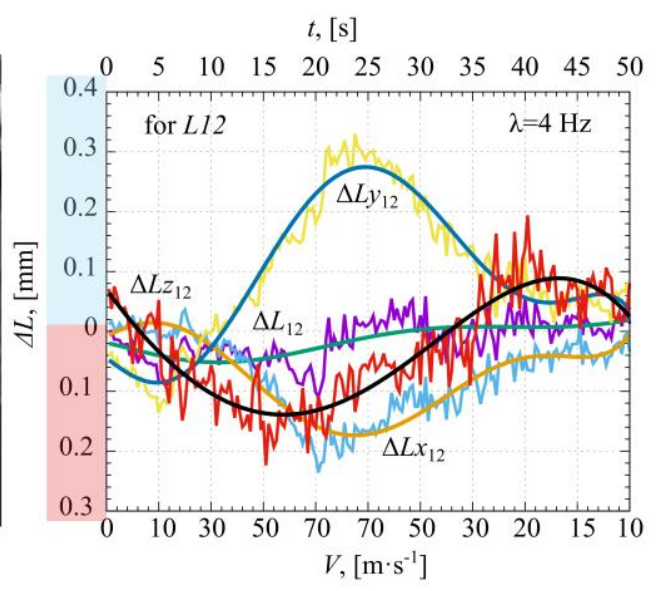

d)

$t,[\mathrm{~s}]$

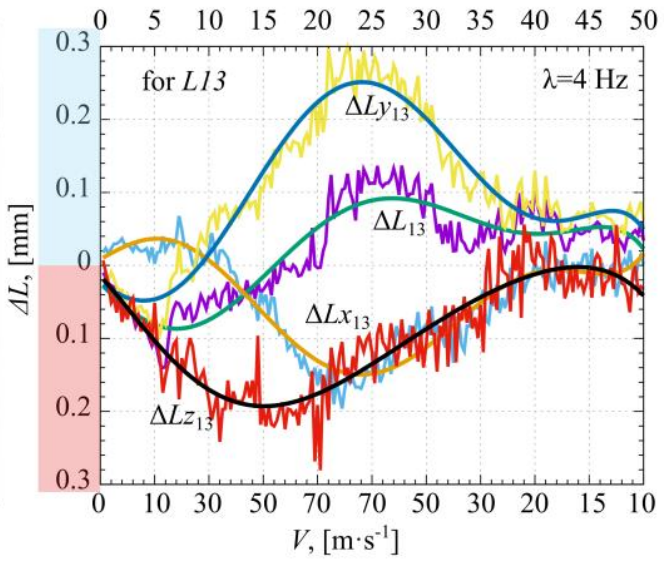

f)

$t,[\mathrm{~s}]$

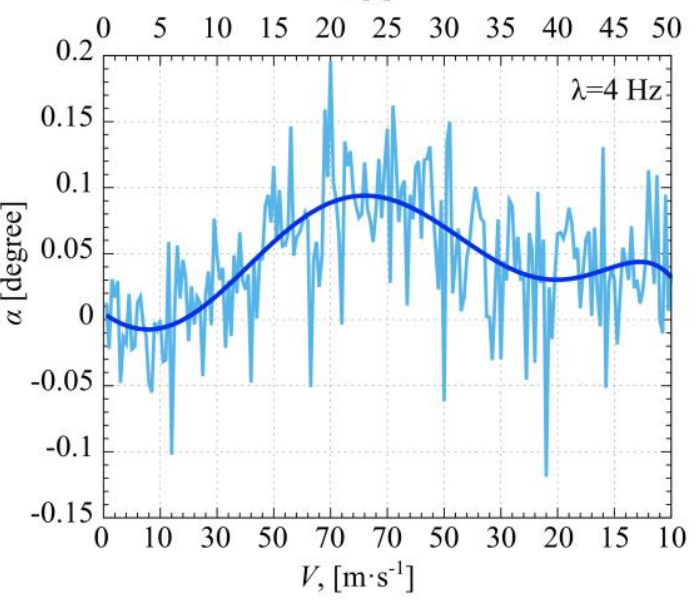

e)

Fig. 7 Estimation of the displacement of the electric motor depending on its operating modes. a) Measuring lines $L 12, L 13$ between the reference points. b), c) Construction of a measuring plane for observing of an angle of inclination of the electric motor. d), f) Displacement at a sharp increase and decrease in flow velocity from 0 to $76 \mathrm{~m} \cdot \mathrm{s}^{-1}$ and then to $5 \mathrm{~m} \cdot \mathrm{s}^{-1}$. e) Dependence of the angle of inclination with a sharp increase and decrease in flow velocity from 0 to $76 \mathrm{~m} \cdot \mathrm{s}^{-1}$ and then to $5 \mathrm{~m} \cdot \mathrm{s}^{-1}$. The blue area shows the elongation of the measuring line, red area of its reduction 

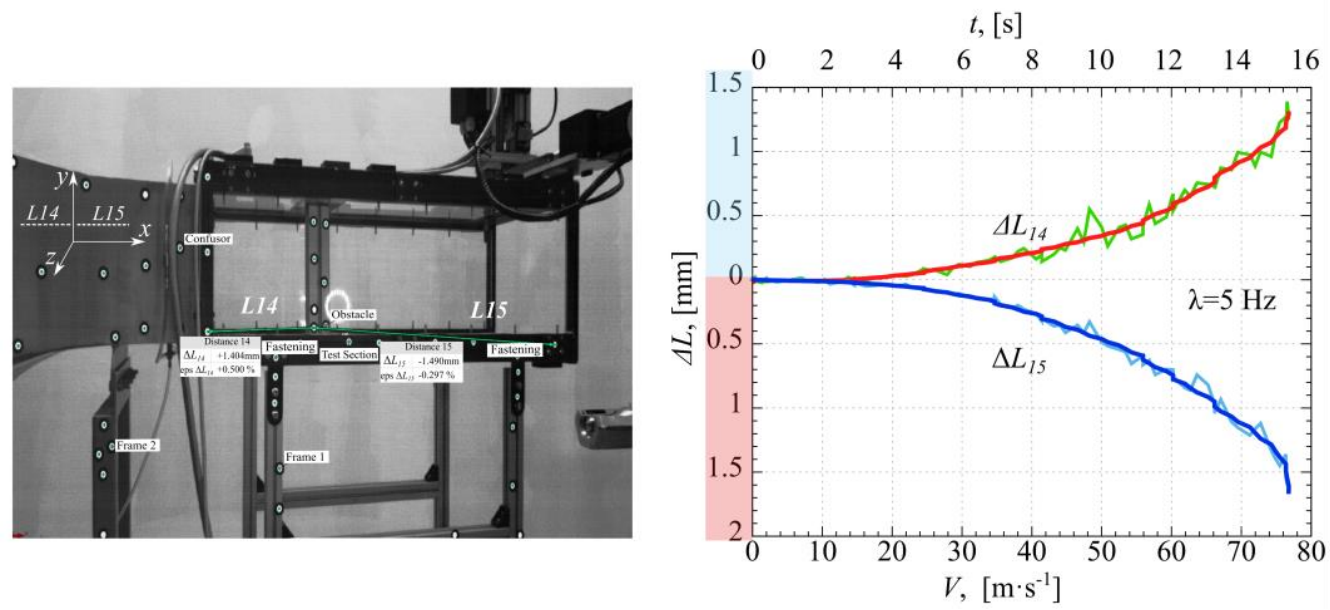

a)
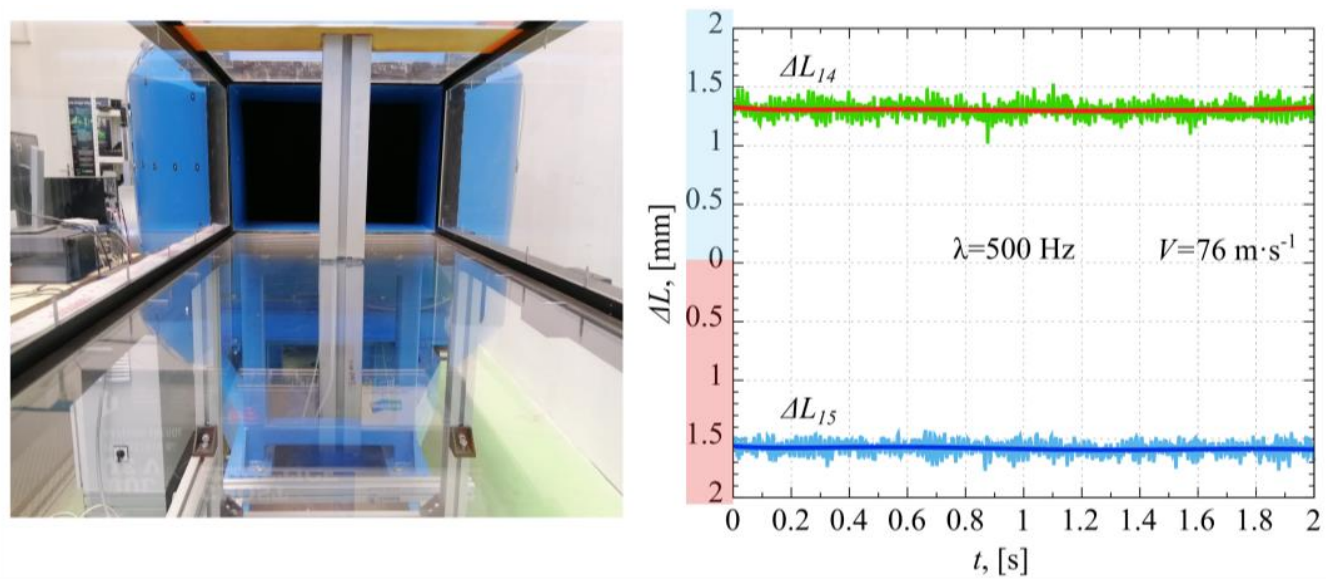

b)

e)

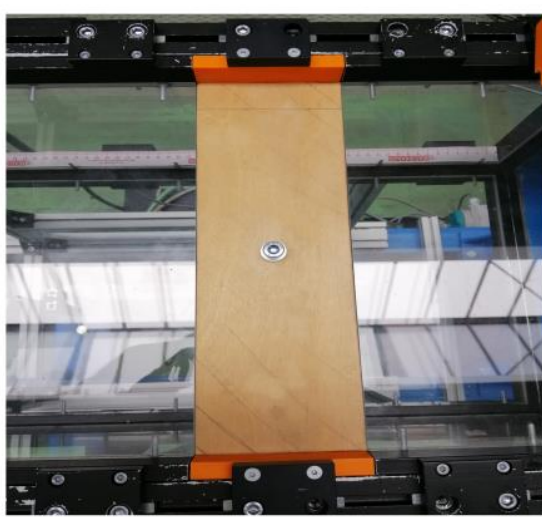

c)

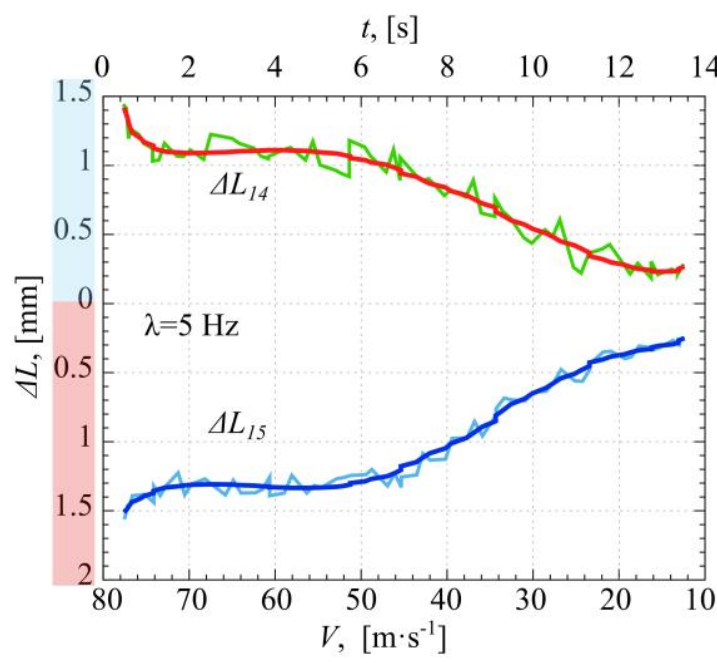

f)

Fig. 8 Estimation of obstacle displacement depending on airflow velocity. a) Measuring lines between the reference points. b) Location of the obstacle in the inside of the test section.

c) Fastening of an obstacle on a wooden part of a covering of the test section. d), f)

Displacement for $\Delta L_{14}$ and $\Delta L_{15}$ at a sharp increase and decrease in flow velocity from 0 to 76 $\mathrm{m} \cdot \mathrm{s}^{-1}$ and then to $5 \mathrm{~m} \cdot \mathrm{s}^{-1}$. e) Displacement at a constant flow velocity $76 \mathrm{~m} \cdot \mathrm{s}^{-1}$. The blue area shows the elongation of the measuring line, red area of its reduction 
We also analyzed the displacement of the motor relative to the three planes $x, y$ and $z$. The recording frequency of the camera was at $\lambda=4 \mathrm{~Hz}$. The obtained experimental results are presented in Fig. $7 \mathrm{~d}$, f, e. In Fig. $7 \mathrm{~d}$ and Fig. $7 \mathrm{f}$ we can see that the displacements of the motor relative to the three axes are very similar. Their maximum value of displacement is observed in the vertical plane for $\Delta L y_{12} \approx \Delta L y_{13} \approx 0.25 \mathrm{~mm}$. We also found that with increasing flow velocity, the motor will shift relative to the horizontal plane by $\alpha \approx 1^{\circ}$ (Fig. 7 e). An example of constructing a measuring plane to determine the angle of the engine is shown in Fig. 7 b, c.
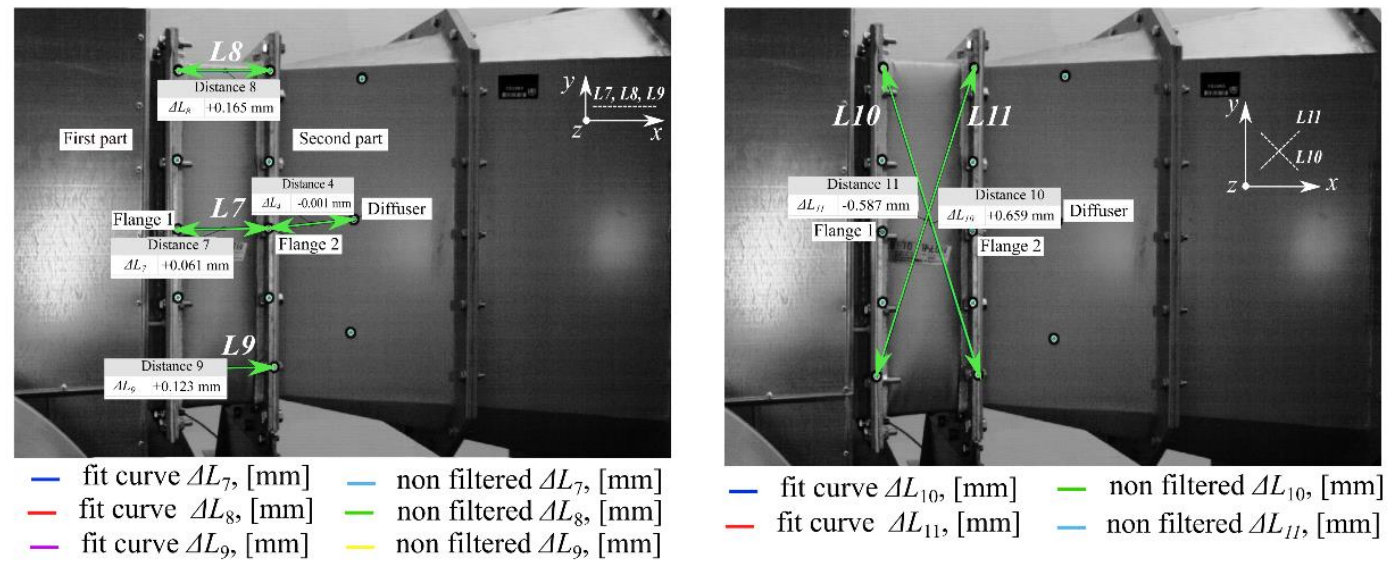

Fig. 8b shows the dependence of the displacement of the obstacle in the form of a square cylinder depending on the air flow velocity. As for previous experimental studies, we analyzed three cases. The first with a sharp increase in flow velocity to $76 \mathrm{~m} \cdot \mathrm{s}^{-1}$ at $\lambda=5 \mathrm{~Hz}$. The second at a constant flow velocity of $76 \mathrm{~m} \cdot \mathrm{s}^{-1}$ at $\lambda=500 \mathrm{~Hz}$. The third with a sharp decrease in flow from $76 \mathrm{~m} \cdot \mathrm{s}^{-1}$ to $10 \mathrm{~m} \cdot \mathrm{s}^{-1}$ at $\lambda=5 \mathrm{~Hz}$. To analyze the obstacle displacement, we generated two measuring lines $L 14$ and $L 15$ between the reference points of the obstacle and the test section (Fig. 8 a). It is worth noting that the obstacle is fixed on a wooden material (see Fig. 8 c). Therefore, its displacement is mainly due to the deformation of the wood material. In Fig. 8d we can see that the maximum obstacle displacement at a sharp increase in flow is for $\Delta L_{14}$ and for $\Delta L_{15}$ is $1.8 \mathrm{~mm}$. The symmetrical distribution of the obtained curves is quite logical. Because they show the displacement of the obstacle relative to the two opposite sides of the test section. At a constant flow velocity of displacement $\Delta L_{14}$ and $\Delta L_{15}$ is $\approx 1.5 \mathrm{~mm}$ (Fig. $8 \mathrm{e}$ ). Accordingly, at sharply reduced flow velocity, the displacement of the obstacle decreases sharply (Fig. $8 \mathrm{f}$ ).

\section{CONCLUSION}

We used the ARAMIS system to study the behavior of the structural parts of the wind tunnel as a function of flow velocity. As a result of the experiment, the amount of displacement of the electrical motor, deformation of the confuser, of the settling chamber, and of the test section. We also investigated the mutual displacement of parts of the wind tunnel to generate and to calm the airflow.

Studies have been done for several cases. In the first case, we sharp increased the flow velocity to $76 \mathrm{~m} \cdot \mathrm{s}^{-1}$ and then sharp reduced the airflow to $10 \mathrm{~m} \cdot \mathrm{s}^{-1}$. In the second case, we investigated the behavior of the tunnel construction at a constant flow velocity of $76 \mathrm{~m} \cdot \mathrm{s}^{-1}$. We also changed the recording frequency of the cameras $\lambda=3-5 \mathrm{~Hz}$ (for the first case) and $\lambda=500 \mathrm{~Hz}$ (for the second case). The results of experimental studies are shown in Table 1 . 
Table 1. Experimental results

\begin{tabular}{|l|l|l|}
\hline $\begin{array}{l}\text { Structural element of the } \\
\text { wind tunnel }\end{array}$ & $\begin{array}{l}\text { At a sharp increase velocity } \\
\text { from } 0 \text { to } 76 \mathbf{m} \cdot \mathbf{s}^{-1}\end{array}$ & At constant velocity $76 \mathbf{m} \cdot \mathbf{s}^{-\mathbf{I}}$ \\
\hline Test section $\left(\boldsymbol{\varepsilon}_{\max }, \boldsymbol{\%}\right)$ & $\varepsilon_{1} \sim 0.011 ; \boldsymbol{\delta}_{2} \sim 0.008$ & $\varepsilon_{1} \sim 0.008 ; \varepsilon_{2} \sim 0.001$ \\
\hline Confuser $\left(\boldsymbol{\varepsilon}_{\max }, \boldsymbol{\%}\right)$ & $\varepsilon_{3} \sim 0.005 ; \delta_{4} \sim 0.006$ & $\varepsilon_{3} \sim 0.004 ; \varepsilon_{4} \sim 0.005$ \\
\hline Settling chamber $\left(\boldsymbol{\varepsilon}_{\max }, \boldsymbol{\%}\right)$ & $\varepsilon_{5} \sim 0.004 ; \delta_{6} \sim 0.012$ & $\varepsilon_{5} \sim 0.001 ; \varepsilon_{6} \sim 0.003$ \\
\hline Coupling $\left(\Delta \boldsymbol{L}_{\max }, \mathbf{m m}\right)$ & $\Delta L_{7} \sim 0.35 ; \Delta L_{8} \sim 0.20$ & $\Delta L_{7} \sim 0.21 ; \Delta L_{8} \sim 0.14$ \\
& $\Delta L 9 \sim 0.22 ; \Delta L_{10} \sim 0.70$ & $\Delta L 9 \sim 0.10 ; \Delta L_{10} \sim 0.60$ \\
& $\Delta L_{11} \sim 0.60$ & $\Delta L L_{11} \sim 0.50$ \\
\hline Electric motor $\left(\Delta \boldsymbol{L}_{\max }, \mathbf{m m}\right)$ & $\Delta L y_{12} \sim 0.28 ; \Delta L y_{13} \sim 0.26 ;$ & $\Delta L y_{12} \sim 0.22 ; \Delta L y_{13} \sim 0.20 ;$ \\
& $\Delta L x_{12} \sim 0.18 ; \Delta L x_{13} \sim 0.16 ;$ & $\Delta L x_{12} \sim 0.16 ; \Delta L x_{13} \sim 0.14 ;$ \\
& $\Delta L z_{12} \sim 0.15 ; \Delta L z_{13} \sim 0.20 ;$ & $\Delta L z_{12} \sim 0.12 ; \Delta L z_{13} \sim 0.15 ;$ \\
\hline
\end{tabular}

As we can see the obtained experimental data for the two measurement cases are different. With a sharp increase in the flow velocity, the values obtained are greater than with a constant flow velocity. This is due to the relaxation properties of the material of the structural parts of the tunnel.

The largest value of displacement we can observe near the elastic coupling. In fact, this value shows how much the section for generating the flow is displaced from the section of the wind tunnel to calm the flow. This phenomenon occurs due to the pressure difference in the above sections.

We also investigated the displacement of the obstacle in the form of a square cylinder depending on the flow velocity. The maximum value of the displacement at a sharp increase velocity flow is $\Delta L_{14} \approx \Delta L_{15} \approx 1.8 \mathrm{~mm}$. In this case, the displacement occurs due to the deformation of the wooden base on which the cylinder is fixed. However, the obtained results allow us to assume that the use of the ARAMIS system is also possible to study the resistance coefficients of thin-walled elements.

In general, we can conclude that the construction of the developed wind tunnel has a very high stiffness to pressure drop. Which may be formed due to the operation of the wind tunnel.

\section{ACKNOWLEDGEMENT}

The work was supported from ERDF under the project Research Cooperation for Higher Efficiency and Reliability of Blade Machines (LoStr) No. CZ.02.1.01/0.0/0.0/16_026/ 0008389.

\section{REFERENCES}

[1] Rae, W. H., Pope, A. "Low-Speed Wind Tunnel Testing, 1st edn”, Wiley-Interscience, New Dallas, USA, 1984. ISBN 10:0471874027

[2] Zambri, H., Ghopa, A. W., Shahrir, A., Izhar, G. M., Amer, A. A., Rasani, M., Rozli, Z. M., Wan, M.M.R., Abu, Zulkhairi, A., Hanna, W. "The development of a multi-purpose wind tunnel", Jurnal Teknologi, 78, pp. 63 - 70, 2016. DOI: 10.11113/jt.v78.9189

[4] Almeida O., Miranda, F. C., Neto, O., Saad, F. G. "Low Subsonic Wind Tunnel - Design and Construction", Journal of Aerospace Technology and Management 10, pp. $1-20$, 2018. DOI: $10.10 .5028 /$ jatm.v10.716. 
[5] Cattafesta, L., Bahr, C. and Mathew, J. "Fundamentals of Wind-Tunnel Design. In Encyclopedia of Aerospace Engineering”, eds R. Blockley and W. Shyy., John Wiley\& Sons Ltd, Gainesville, Florida, USA, 2010. DOI: 10.1002/9780470686652.eae532

[6] Celis, B., Ubbens, H. H. "Design and Construction of an Open-circuit Wind Tunnel with Specific Measurement Equipment for Cycling”, Procedia Engineering 147, pp. 98 - 103, 2016. DOI: $10.1016 /$ j.proeng.2016.06.196

[7] Mehta, R. D., Bradshaw, P. "Design rules for small low speed wind tunnels", Aeronautical Journal, Volume 83 (827), pp. 443 - 453, 1979. DOI: $10.1017 / \mathrm{S} 0001924000031985$

[8] Bradshaw, P., Pankhurst R. "The design of low-speed wind tunnels", Progress in Aerospace Sciences 5, pp. 1 - 69, 1964. DOI: 10.1016/0376-0421(64)90003-X

[9] Barlow, J. B., Rae, W. H., Pope, A. "Low-Speed Wind Tunnel Testing, 3rd edn", John Wiley Sons, New York, USA, 1999. ISBN 0471557749

[10] Teseletso, A., Namoshe, M., Subaschandar, N., Kutua, S. "Design of an Open-circuit Subsonic Wind Tunnel for Educational Purpose", Botswana Institution of Engineers (BIE) 14th International Biennial Conference, At Phakalane, Botswa, 2015. https://www.researchgate.net/publication/311922668

[11] Uruba, V. “(An) Anisotropy analysis of turbulence”, Topical Problems of Fluid Mechanics, Praha, Czech Republic, pp. 237 - 244, 2015.

[12] Tropea, C., Yarin, A., Foss, J. F. "Springer Handbook of Experimental Fluid Mechanics", Springer, Heidelberg, Germany, 2007. DOI: 10.1007/978-3-540-30299-5

[13] Pope, S. B. "Turbulent flows", Cambridge University Press, Cambridge, United Kingdom of Great Britain, 2000. DOI: 10.1017/CBO9780511840531

[14] Batchelor, G. K. "The Theory of Homogeneous Turbulence”, Cambridge University Press, New York, USA, 1953. DOI: 10.1002/qj.49707934126

[15] Bourgoin, M., Baudet, C., Kharche, S. et al. "Investigation of the small-scale statistics of turbulence in the Modane S1MA wind tunnel", CEAS Aeronaut 9, pp. 269 - 281, 2018. DOI: $10.1007 / \mathrm{s} 13272-017-0254-3$

[16] Gogola, R., Murín, J., Hrabovský, J. "Numerical calculation of overhead power lines dynamics", Strojnícky časopis - Journal of Mechanical Engineering 66 (2), pp. 13 - 22, 2016. DOI: $10.1515 /$ scjme-2016-0014

[17] Jablonská, J., Kozubková, M., Zavadilová, B., Zavadil, L., Fialová, S. “The investigation of the cavitation phenomenon in the laval nozzle with full and partial surface wetting", Strojnícky časopis - Journal of Mechanical Engineering 67(1), pp. 55 - 68, 2017. DOI: $10.1515 /$ scjme-2017-0006

[18] Schairer, E. T., Kushner, L. K., Garbeff, T. J., Heineck, J. T. "Model Deformation Measurements of Sonic Boom Models in the NASA Ames 9- by 7- Ft Supersonic Wind Tunnel”, 53rd AIAA Aerospace Sciences Meeting, Kissimmee, Florida, USA, pp. 1 15, 2015. DOI: $10.2514 / 6.2015-1913$

[19] Liu, T., Montefort, J., Gregory, J., Palluconi, S., Crafton, J., Fonov, S. "Wing Deformation Measurements from Pressure Sensitive Paint Images Using Videogrammetry", 41st AIAA Fluid Dynamics Conference and Exhibit, Honolulu, Hawaii, pp. 1 - 31, 2011. DOI: 10.2514/6.2011-3725 
[20] Yanovych. V., Duda. D., Horacek. V., Uruba. V. "Creation of recombination corrective algorithm for research of a wind tunnel parameters", 38th Meeting of Departments of Fluid Mechanics and Thermodynamics, Wellness and Kongress Hotel CHOPOK Liptovsky Mikulas, Slovakia, pp. 1 - 31, 2019. DOI: 10.1063/1.5114778

[21] Yanovych, V., Duda, D., Horáček, V., Uruba, V. "Research of a wind tunnel parameters by means of cross-section analysis of air flow profiles", 18th Conference of Power System Engineering, Thermodynamics and Fluid Mechanics 2189(1):020024, 2019. DOI: $10.1063 / 1.5138636$

[22] Yanovych, V., Duda, D., Uruba, V. "Structure turbulent flow behind a square cylinder with an angle of incidence", European Journal of Mechanics, B/Fluids 85, pp. 110 123, 2021. DOI: $10.1016 /$ j.euromechflu.2020.09.003 